\title{
Sıklık bakımının doğal sarıçam (Pinus sylvestris L.) meşcerelerinde çap ve göğüs yüzeyi üzerine etkisi
}

\author{
Ömer ÖNCÜL ${ }^{1 *}$, Çağlar UĞURLU1 ${ }^{1}$ Dr. Murat KÖSE ${ }^{1}$, Prof. Dr. Fahrettin TÍLKí ${ }^{2}$ \\ ${ }^{1}$ Doğu Anadolu Ormancılık Araştırma Enstitüsü Müdürlüğü 25050, ERZURUM \\ ${ }^{2}$ Artvin Çoruh Üniversitesi Orman Fakültesi 08000, ARTVIN
}

"Sorumlu yazar/Corresponding author: omeroncul@ogm.gov.tr, Geliş tarihi/Received: 18.03.2016, Kabul tarihi/Accepted: 20.06 .2016

Öz

Bu çalışmada, idare süresi sonunda işletme amacına uygun nitelikte ve ekonomik getirisi yüksek meşcereler oluşturabilmek için, sıklık çağındaki doğal sarıçam meşcerelerinde bakım tedbirleri sonucu, hektarda olması gereken göğüs yüzeyi miktarını ve birey sayısını belirlemek amaçlanmıştır. Bu amaçla Sarıkamış ve Ardahan'da belirlenen iki deneme alanında (18-20 yaş aralığında) dört işlem (kontrol, zayıf, orta ve kuvvetli müdahale işlemi) ve üç tekerrürden oluşan her biri $500 \mathrm{~m}^{2}$ 'lik toplam 24 parsel oluşturulmuştur. Zayıf müdahale parselinde alandaki toplam göğüs yüzeyinin \%10-15'i, orta müdahale parselinde \%20-25’i ve kuvvetli müdahale parselinde ise \%30-35'i çıkarılmış, kontrol parsellerinde herhangi bir müdahale yapılmamıştır. Deneme parsellerindeki bireylerde 2010 y1lı ilkbaharında başlangıç çap değerleri ölçülmüş ve işlemlere göre müdahale kesimleri yapılarak, 2013 yılı ilkbaharındaki çap değerleri ile karşılaştırılıp her iki müdahale yılı arasındaki gelişim farkı tespitleri yapılmıştır. Elde edilen sonuçlara göre; yapılan sıklık bakımı müdahalelerinin gelişmeye etkisinin olduğu ve bu etkinin çap ve göğüs yüzeyi değerleri açısından en iyi gelişiminin kuvvetli müdahale işleminde gerçekleştiği tespit edilmiştir. Çalışma sonucunda, genel olarak 18-20 yaşlarındaki doğal sarıçam meşcerelerinde sıklık bakımı yapılan alanlarda ilk sıklık bakımı kesimlerinde hektardaki birey sayısının 3000-4000 adet civarında tutulması çap ve göğüs yüzeyi açısından en iyi sonucu vermektedir.

Anahtar Kelimeler: Çap, göğüs yüzeyi, sarıçam, sıklık bakımı.

\section{Effects of precommercial thinning on stem diameter and basal area in natural stands of Scots pine (Pinus sylvestris L.)}

\begin{abstract}
Eastern Anatolia Region have natural Scots pine stands which provide smooth and quality yield and optimal growth in addition to its possibility to see stands with forked, thin, enormous, bad-shaped, non-growth trees. Precommercial thinning is a practical means of substantially increasing the production of usable wood. This study aims to determine the effects of precommercial thinning on Scots pine stand (18-20 years old). Precommercial thinning experiments were established in Scots pine stands in Sarıkamıs and Ardahan in 2010. The experimental plots are $3 \times 4 \times 500=$ $6000 \mathrm{~m}^{2}$ in each site. Three thinning treatments (light, moderate and heavy) and a control area were randomly assigned to adjacent areas, approximateley 0.6 ha in size in each site. There are a total of 12 plots in each experiment area (3 replicates, 4 treatments per replicate). The effects of the treatments were analysed after a period of 3 years. The study showed that heavy precommercial thinning (30-35\%reduction in basal area) resulted in the highest diameter and basal area in both areas. That there are left 3000-4000 stems / ha after the first precommercial thinning in Scots pine is recommended.
\end{abstract}

Keywords: Diameter, basal area, Scots pine, precommercial thinning.

To cite this article (Atıf): ÖNCÜL Ö., UĞURLU Ç., KÖSE M., TİLKİ F., 2016. Sıklık bakımının doğal sarıçam (Pinus sylvestris L.) meşcerelerinde çap ve göğüs yüzzeyi üzerine etkisi. Orman Genel Müdürlüğü Ormanc1lık Araştırma Dergisi 1(3):29-37 DOI: 10.17568/oad.16929

\section{Giriş}

Çam türleri içerisinde en geniş coğrafi yayılışa sahip türlerden olan Sarıçam (Pinus sylvetsris L.) Avrupa ve Asya'da yaklaşık $2700 \mathrm{~km}$ eninde ve 1400 $\mathrm{km}$ uzunluğunda çok geniş bir coğrafik yayılışa sahiptir. Kuzey sınırı 70. coğrafi enleme (Kuzey İskandinavya), Güney sınırı yaklaşık 37. kuzey enleminde (İspanya), Batı sınırı yaklaşık 8 . batı boy- lamında (İspanya) ve Doğuda ise 141. doğu boylamına (Rusya) kadar uzanmaktadır (Pravdin, 1969; Boratynski, 1991; Skilling, 1990).

Ülkemizde Eskișehir'in batısından başlayıp Sarıkamış üzerinden Kafkaslara geçen Sarıçam, 380 34'410 48' Kuzey enlemler ile 280 00'-430 05’ Doğu boylamları arasında doğal bir yayılışa sahiptir. 1000-2500 m'ler arasında saf ve diğer orman ağacı 


\section{Effects of precommercial thinning on stem diameter and basal area in natural stands of Scots pine (Pinus sylvestris L.)}

türleri ile karışık olarak yayılış göstermektedir. Sarıçamın dikey yayılışı Sürmene-Trabzon'da deniz seviyesinden, Kars-Sarıkamış'ta 2700 m’ye kadar çıkmaktadır (Kayacık, 1963; Saatçığlu, 1976). Sıklık çağı, meşcere kapalılığının teşekkülünden kuvvetli dal budanması ve gövde ayrılmasının başlamasına kadar geçen süredir ve bu çağda yapılan bakım çalışmaları da sıklık bakımlarıdır (Saatçioğlu, 1971). Başka bir ifadeyle, sıklık bakımı, meşcerenin gençlik çağından sıklık çağına geçişiyle başlayan, gerektiğinde yinelenerek sırıklık çağına kadar devam eden silvikültürel bir işlemdir (Saatçioğlu, 1971; Atay, 1984). S1klık bakımının en önemli amacı, geleceğin değer ağacını bugünden belirlemek, onu kolayca tanınır ve bulunur duruma getirmek, bu ağaçlara serbest yaşama alanı vermek, 1 şı ve hava ihtiyaçlarını sağlamak, karışım söz konusu ise meşcere karışımını işletme amacına uygun düzenlemek ve meşcere perdesinin bakımını yapmaktır. Sıklık bakımlarında, kesimlerin ağırlık noktası, esas itibariyle işe yaramayan fertler üzerinde toplanır (menfi seleksiyon). Sıklık çağındaki meşcerede birey sayısı çok fazladır. Geleceğin kıymet ağaçlarını müdahale öncesi belirleyebilmek oldukça güçtür. Söz konusu iyi vasıflı fertleri korumak üzere öncelikle hasta, yaralı, cılız, ölmüş ve ölmek üzere olanlar çıkartıldıktan sonra, açık bir şekilde ayırt edilebilen, kıymetçe düşük, bütün fena gövde şekilli (kısa, yamuk, çatallı) fertlerle, üst tabakada meşcere kuruluşuna katılmaları arzu edilmeyen fertler, sıklıktan çıkartılır (Atay, 1971; Saatçioğlu, 1971).

S1klık bakımlarına konu olan alanlar (amenajman planlarında a veya ab rumuzu ile gösterilen çağlarda) amenajman planlarında eta verilmeyen alanlardır. Bu alanlarda çalışmanın ekonomisi ve yoğunluğu düşünülürse, belki de sıklık bakım çalışmaları daha az gerekli bir çalışma olarak görülebilir. Ancak, sıklık bakımlarının meşcereye ve nihayetinde amaca varmadaki olumlu etkileri de yapılan çalışmalarda ortaya konmuştur. Sıklık bakımlarındaki ilk müdahalede çıkarılan ürün ekonomik olarak çok büyük bir değer ifade etmeyebilir ancak sonraki müdahalelerden elde edilen ürünlerin değerlendirilmesini mümkün kılacaktır. Ayrıca, sıklık bakımlarının meşcere gelişimi üzerindeki olumlu etkileri ortaya konulduğunda, bu çalışmaların ihmal edilmemesi gerektiği açıkça görülecektir.

Genç sarıçam meşcerelerinde sıklık bakımı kesiminin en önemli ve araştırılan etkileri, zamanı ve yoğunluğunun ürün ve kalite üzerine etkileridir. Genel olarak araştırmalarda, ürün üzerine etkisi bakımından; çap, boy, hacim ve göğüs yüzeyindeki artış değerleri, kalite bakımından ise gövde formu ve yapısı, dallılık ve dal çapı gibi değerler göz önünde bulundurulmaktadır.

Erken ve hafif sıklık bakımı kesimleri yapılan meşcerelerde $\left(\mathrm{h}_{\text {üst }} 3 \mathrm{~m}, 3000\right.$ gövde/ha), geç ve yoğun sıklık bakımı kesimi yapılan meşcerelere $\left(h_{\text {üst }} 7 \mathrm{~m}\right.$, 2000 gövde/ha) oranla ilk aralama kesimlerinde çıkarılan ürün bakımından $\% 40$ daha fazla ürün sağlamıştır (Huuskonen ve Hynynen, 2006). Ayrıca, erken sıklık bakımı kesimlerinden yüksek dikili hacim ve fazla kullanılabilir odun oranı elde edilmektedir (Varmola ve Salminen, 2004).

Amaç odun üretimini maksimum düzeye çıkarmak ise erken ve yoğun sıklık bakımı kesimleri önerilmektedir (Vuokila, 1972; Parviainen, 1978; Huuskonen ve Hynynen, 2006). Ancak, amaç yüksek kaliteli ürün elde etmekse geç sıklık bakımı kesimlerinin uygulanması önemle vurgulanmaktadir (Vuokila, 1972; Pariainen, 1978; Varmola ve Salminen, 2004).

Finlandiya ormancılığında sarıçam'da amacın hem kaliteli hem de fazla ürün elde edilmesi durumunda hektarda birakılması gereken gövde sayısını Parvianen (1978) 2000-2400, Varmola ve Salminen (2004) 2000-2200 ve Ruha ve Varmola (1997) 2500 adet olarak önermektedir. İsveç ormancıl1ğında ise alanda bırakılacak gövde sayısı ürün verimliliğine dayandırılmaktadır. Verimli alanlarda 2000 , orta derecede verimli alanlarda 2300 ve verimsiz alanlarda 2500 gövde/ha bırakılması önerilmektedir (Varmola ve Salminen, 2004).

Finlandiya'da Özel ormanlarda doğal sarıçam gençliklerinde dominant boy 4-7 m olduğu durumda 1800-2000 birey/ha olacak şekilde sıklık bak1mı önerilmektedir (Luonnonlahinen 1994'e atfen Ruha ve Varmola, 1997). Devlet ormanlarında bu değer ortalama boy 3-6 m olduğu durumda 16002000 birey/ha olarak önerilmiştir (Metsanhoitosuositutsten 1994'e atfen Ruha ve Varmola, 1997).

Gövde kalitesi üzerine hem sıklık bakımı kesiminden önceki, hem de sonraki meşcere sıklığının önemli bir etkisi vardır. Ruha ve Varmola (1997), sıklık bakımı kesimlerinden 5-10 yıl sonra kesim anında hektarda 3000-5000 gövde bulunan meşcerede tepe tacı dip kütüğündeki en kalın dal çap1 ortalamada hektarda 6000-10000 gövde bulunan meşceredeki tepe tacı dip kütüğündeki dalların çapından $8 \mathrm{~mm}$ daha kalın olduğunu belirtmektedirler. Meşcere sıklığının fazla olması, dal ölümlerinin fazla olmasına ve böylece tepe tacının kısa ömürlü olmasına, ayrıca, düşük dal çaplarının oluşmasına sebep olmaktadır (Johansson, 1992; Makinen, 1996, Ulvcrona ve ark., 2007). S1klık bakımı kesimlerinden sonra meşcere sıklığının birden bire değişmesi ile tepe tacı oranı (tepe uzunlu- 


\section{Sıklık bakımının doğal sarıçam (Pinus sylvestris L.) meşcerelerinde çap ve göğüs yüzeyi üzerine etkisi}

ğu/gövde boyu) birkaç yıl boyunca kademeli olarak değişmektedir (Hynynen, 1995; Ulvcrona ve ark., 2007). Bu nedenle tepe tacı oranı meşcerenin kesimlerden önceki ve sonraki sıklığından etkilenmektedir.

Sarıçam meşcerelerinin iyi bonitetlerde doğal gençleşme çağına 100-120 yaşlarında (çap 50 cm'den yukarı) ulaşabildikleri, kötü bonitetlerde ise bu sürenin yaklaşık iki katı kadar bir zamana ihtiyaç duyduklarından ancak meşcere kuruluşundan itibaren yapılacak düzenli bakım tedbirleri ile söz konusu sürelerin kısaltılmasının yani amaç çapına daha erken yaşlarda ulaşılmasının mümkün olduğundan söz edilmektedir (Karadağ,, 2013).

Sedir meşcerelerinde sıklık derecesinin arttırılmasıyla bu artım ve hacimleri, meşcerenin bonitet derecesinin izin verdiği ölçüde en yüksek düzeye çıkarmanın ve aynı yaşlı ormanlarda belli yaştaki normal kapalı bir meşcerenin mevcut sıklık derecesini, meşceredeki mevcut ağaçlardan yararlanarak, yükseltmek veya küçültmenin mümkün olduğunu, meşcereyi istenen bir sıklık derecesine yükseltmek için bu sıklık derecesine karşı gelen ağaç sayısının bulunduğu yaşa kadar meşcereye herhangi bir silvikültürel işlem uygulamamak gerektiğini, sıklık derecesi değerini küçültmek için ise uygun silvikültürel işlemlerle meşceredeki ağaç sayısını, sıklık derecesi değerine karşı gelen ağaç sayısına ininceye kadar aralamalarla azaltma yoluna gidilmesi gerektiğinden bahsedilmektedir (Y1ldıbakan ve ark., 2013).

Avrupa ormancılığında, genç sarıçam meşcerelerinde sıklık bakımı kesimleri üzerine yapılan araştırmalar sonucu elde edilen veriler, sarıçamın tür özelliği sebebiyle ülkemiz ormancılığı için de uygulanabilir niteliktedir. Ancak, araştırmaların genelde yükselti ve bakı farkı barındırmayan Avrupa ormanlarında gerçekleştirilmiş olması, bu farkl1lıkları fazlasıyla barındıran ülkemiz ormancılığ için de benzer araştırmaların yapılmasını gerekli kılmıştır.

\section{Materyal ve Yöntem}

\subsection{Materyal}

Çalışmadaki deneme alanlarından biri Sarıkamış Orman İşletme Müdürlüğü, Merkez İşletme Şefliği, 14 No'lu bölme içerisinde (N: 410 02' 680", E: 420 34' 863"), diğeri ise Ardahan Orman İşletme Müdürlüğü, Yalnızçam İşletme Şefliği, 66 No'lu bölme içerisindedir (N: 400 18' 812", E: 420 35' 678'). Deneme alanlarındaki sarıçam meşcerelerinin yaşı 18-20 arasında olup, bakıları kuzey - kuzeybat1, II. bonitet'de, eğimleri \%30-55 arasında değişmekte ve her iki deneme alanının civarında doğal sarıçam meşcereleri bulunmaktadır.

İklim özellikleri olarak, uzun yıllar ortalamalarına göre ölçülen en yüksek ve en düşük sıcaklıklar Sarıkamış'ta $35,4{ }^{\circ} \mathrm{C}$ ile $-33,1{ }^{\circ} \mathrm{C}$ Ardahan'da ise $35,0{ }^{\circ} \mathrm{C}$ ile $-37,8{ }^{\circ} \mathrm{C}$ 'dir. Ortalama yağışlı gün sayısı Sarıkamış'ta 129,8 iken, Ardahan'da 130,8 gündür. Ölçülen en yüksek kar yağışı Sarıkamış’ta 88 cm, Ardahan'da ise $110 \mathrm{~cm}$ 'dir. Sarıkamış'taki deneme alanının rakımı 2120 m, Ardahan'daki deneme alanının rakımı ise 1990 m'dir. Deneme alanlarında herhangi bir böcek zararına rastlanmamıştır.

Çalışmaya başlamadan önce, deneme alanlarında yapılan sayımlara göre, Sarıkamış'ta $\mathrm{m}^{2}$ 'de ortalama 4 adet, Ardahan'daki deneme alanında ise 5 adet fidan tespit edilmiştir. Deneme alanlarında tesadüfen ölçülen 100 fidanın ortalama boyu Sar1kamış'ta 4.1 m ve dipçapı $4.3 \mathrm{~cm}$; Ardahan'daki deneme alanında boy $4.6 \mathrm{~m}$ ve dipçapı $3.9 \mathrm{~cm}$ olarak belirlenmiştir.

\subsection{Yöntem}

Deneme, rastlantı blokları deneme desenine göre üç tekerrürlü kurulmuştur. Her bir deneme alanı 4 işlem (kontrol, zayıf, orta ve kuvvetli müdahale) ve 3 tekerrür olmak üzere 3 x 4 x $500=6000 \mathrm{~m}^{2}$ 'dir. Her parsel dört eşit parçaya bölünmüş ve birisi kontrol olmak üzere diğer üç işlemde zayıf, orta ve kuvvetli derecelerde müdahalelerin yapıldığ 1 iki deneme alanı kurulmuştur.

Kontrol işleminde herhangi bir müdahale yapılmadan alandaki bireyler muhafaza edilmiş olup diğer üç işlemde zayıf, orta ve kuvvetli derecelerde müdahaleler yapılmıştır. Zayıf müdahale işleminde, parseldeki toplam gögüs yüzeyinin $\% 10-15$ 'i; orta müdahale işleminde parseldeki gögüus yüzeyinin \%20-25'i; kuvvetli müdahale işleminde ise parseldeki göğüs yüzeyinin \%30-35'i çıkarılarak yapılan müdahalelerin gelişim üzerine etkisi belirlenmeye çalışılmıştır. 2010 yılı ilkbaharı ve 2013 yılı ilkbaharındaki üç vejetasyon dönemi sonunda elde edilen veriler bu çalışma ile değerlendirilmektedir. Silvikültürel esaslar çerçevesinde yapılan müdahalelerde ağaçların alanda homojen dağılımına özen gösterilmiştir.

\section{Bulgular ve Tartışma}

Yapılan müdahalelerin çap gelişimi üzerinde istatistiksel olarak etkisinin olup olmadığını test edebilmek için 2010 yılı başlangıç çap değerleri ve 2013 y1lı çap değerleri SPSS 20,0 v paket programında karşılaştırılıp, varyans analizi yapılarak Tablo 1'deki değerler elde edilmiştir. 


\section{Effects of precommercial thinning on stem diameter and basal area in natural stands of Scots pine (Pinus sylvestris L.)}

Varyans analizinden elde edilen sonuçlar, yıl x blok etkileşimi ile yıl x blok x müdahale şekli etkileşimi dışındaki diğer bütün etkileşimlerin anlamlı olduğunu göstermektedir.

Müdahale şekli (kontrol, zayıf, orta ve kuvvetli) ve deneme alanı (Sarıkamış ve Ardahan) çap gelişimi üzerinde etkili olmuştur.

Sarıkamış deneme alanında 2010-2013 yılları arasında 4 farklı müdahale işlemi değerlendirildiğinde kontrol grubunda \%30,4 çap artımı elde edilirken zayıf, orta ve kuvvetli müdahale görmüş alanlarda bu değerler sırasıyla \%32,4; 35,1 ve \%40,1 olarak tespit edilmiştir. En yüksek çap artış1 \%40,1 ile kuvvetli müdahale işlemi görmüş alanda elde edilmiştir (Tablo 2). Çap üzerinde müdahale şeklinin etkili olduğu ve 2013 yılında en yüksek çap değerinin Orta ve Kuvvetli müdahale işlemleri sonucu elde edildiği görülmektedir.

2010 ve 2013 çap değerleri Sarıkamış deneme alanında birlikte değerlendirildiğinde, yapılan müdahalelerin çap gelișimi üzerinde etkili olduğu ve en iyi gelişimin orta ve kuvvetli müdahale işlemlerinde gerçekleştiği görülmektedir (Tablo 2).

Ardahan deneme alanında 2010-2013 yılları arasında 4 farklı müdahale işlemi değerlendirildiğinde kontrol grubunda $\% 50$ ve zayıf müdahale görmüş alanda \%47,7 çap artımı elde edilirken orta müdahale görmüş alanda $\% 56,8$ ve kuvvetli müdahale görmüş alanda \%58,1 oranında çap artımı elde edilmiştir (Tablo 4). Çap üzerinde müdahale şeklinin etkili olduğu ve 2013 yılında en yüksek çap değerinin Kuvvetli müdahale işlemi sonucu elde edildiği belirlenmiştir $(6.64 \mathrm{~cm})$.

Tablol. Müdahale şekillerinin çap gelişimi etkisine ilişkin varyans analizi Table 1. Results of ANOVA for diameter by treatment

\begin{tabular}{llcrrc}
\hline \multicolumn{1}{c}{ Kaynak } & $\begin{array}{l}\text { Kareler } \\
\text { Toplam1 }\end{array}$ & df & $\begin{array}{c}\text { Kareler } \\
\text { Ortalamas } 1\end{array}$ & F & $\begin{array}{c}\text { Önem } \\
\text { Seviyesi }\end{array}$ \\
\hline Y11 & 16254,603 & 1 & 16254,603 & 3258,796 & 0,000 \\
Blok & 14759,796 & 1 & 14759,796 & 2959,110 & 0,000 \\
Müdahale Şekli & 1426,640 & 3 & 475,547 & 95,340 & 0,000 \\
Y11 * Blok & 1,037 & 1 & 1,037 & 0,208 & 0,648 \\
Y11 * Müdahale Şekli & 264,230 & 3 & 88,077 & 17,658 & 0,000 \\
Blok * Müdahale Şekli & 99,490 & 3 & 33,163 & 6,649 & 0,000 \\
Y11 * Blok * Müdahale Şekli & 4,212 & 3 & 1,404 & 0,282 & 0,839 \\
Hata & 94700,597 & 18986 & 4,988 & & \\
Toplam & 655926,040 & 19004 & & & \\
\hline
\end{tabular}

Tablo 2. Sarıkamış deneme alanındaki birey sayıları, ortalama çap değerleri ve artış yüzdeleri

Table 2. Number of stems, mean diameter at breast height and percent of increment at Sarikamis experimental area

\begin{tabular}{lccccc}
\hline \multirow{2}{*}{ Müdahale Şekli } & \multicolumn{2}{c}{2010 y1li } & \multicolumn{2}{c}{2013 y1lı } & Artı̧ \\
\cline { 2 - 5 } & $\begin{array}{c}\text { Birey } \\
\text { Sayıs1 }\end{array}$ & $\begin{array}{c}\text { Ortalama } \\
\mathrm{d}_{1 \cdot 30} \text { çap }(\mathrm{cm})\end{array}$ & $\begin{array}{c}\text { Birey } \\
\text { Say1s1 }\end{array}$ & $\begin{array}{c}\text { Ortalama } \\
\mathrm{d}_{1 \cdot 30} \text { çap }(\mathrm{cm})\end{array}$ & $\begin{array}{c}\text { Ÿzdesi } \\
(\%)\end{array}$ \\
\hline Kontrol & 970 & 5,56 & 838 & 7,25 & 30,4 \\
Zayıf Müdahale & 1034 & 5,86 & 644 & 7,76 & 32,4 \\
Orta Müdahale & 888 & 5.92 & 577 & 8,00 & 35,1 \\
Kuvvetli Müdahale & 947 & 5,93 & 534 & 8,31 & 40,1 \\
\hline
\end{tabular}

Tablo 3. Müdahale şeklinin Sarıkamıs ve Ardahan deneme alanında çap $(\mathrm{cm})$ üzerine etkisi Table 3. Effects of treatments on mean diameter at Sarikamis and Aradahan experimental area

\begin{tabular}{lcccc}
\hline \multirow{2}{*}{ İşlem } & \multicolumn{2}{c}{ Sarıkamış } & \multicolumn{2}{c}{ Ardahan } \\
\cline { 2 - 5 } & Birey Sayısı & Çap & Birey Sayı1s & Çap \\
\hline Kontrol & 1808 & $6,347 \mathrm{c}$ & 3858 & $4,298 \mathrm{~d}$ \\
Zayıf Müdahale & 1678 & $6,590 \mathrm{~b}$ & 3201 & $4,493 \mathrm{c}$ \\
Orta Müdahale & 1465 & $6,738 \mathrm{ab}$ & 2963 & $4,630 \mathrm{~b}$ \\
Kuvvetli Müdahale & 1481 & $6,782 \mathrm{a}$ & 2550 & $5,000 \mathrm{a}$ \\
\hline
\end{tabular}

Aynı sütün üzerinde bulunan benzer harfler arasında istatistik anlamda fark yoktur $(\mathrm{p}<0.05)$. 


\section{Sıklık bakımının doğal sarıçam (Pinus sylvestris L.) meşcerelerinde çap ve göğüs yüzeyi üzerine etkisi}

Müdahalelerin çap gelişimi üzerine etkisi iki farklı alanın ortalaması dikkate alınarak değerlendirildiğinde, müdahale şeklinin çap gelişimi üzerinde aynı yaştaki (18-20 yaş) her iki deneme alanında da benzer şekilde etkili olduğu ve en iyi çap gelişiminin Sarıkamış deneme alanında kuvvetli müdahale işleminde olduğu belirlenmiştir (Tablo 3).

Tablo 4. Ardahan deneme alanındaki birey sayıları, ortalama çap değerleri ve artı̧̧ yüzdeleri

Table 4. Number of stems, diameter at breast height and percent of increment at Ardahan experimental area

\begin{tabular}{lccccc}
\hline & \multicolumn{2}{c}{2010 y1l1 } & \multicolumn{2}{c}{2013 y1lı } & Artı̧ \\
\cline { 2 - 5 } \multicolumn{1}{c}{ Müdahale Şekli } & $\begin{array}{c}\text { Birey } \\
\text { Sayıs1 }\end{array}$ & $\begin{array}{c}\text { Ortalama } \\
\mathrm{d}_{1 \cdot 30} \text { Çap } \\
(\mathrm{cm})\end{array}$ & $\begin{array}{c}\text { Birey } \\
\text { Say1s1 }\end{array}$ & $\begin{array}{c}\text { Ortalama } \\
\mathrm{d}_{1 \cdot 30} \text { Çap } \\
(\mathrm{cm})\end{array}$ & $\begin{array}{c}\text { Yüzdesi } \\
(\%)\end{array}$ \\
\hline Kontrol & 2265 & 3,56 & 1593 & 5,34 & 50,0 \\
Zayıf Müdahale & 1835 & 3,92 & 1128 & 5,79 & 47,7 \\
Orta Müdahale & 2083 & 3,75 & 1118 & 5,88 & 56,8 \\
Kuvvetli Müdahale & 1712 & 4,20 & 838 & 6,64 & 58,1 \\
\hline
\end{tabular}

Tablo 5. Deneme parsellerinde 2010 ve 2013 y1llarındaki göğüs yüzeyi miktarı ve birey sayıları Table 5. Basal area and number of stems in 2010 - 2013 at each experimental site

\begin{tabular}{|c|c|c|c|c|c|c|c|c|}
\hline $\begin{array}{l}\text { Deneme Alan1- } \\
\text { Parsel No: }\end{array}$ & $\begin{array}{l}\text { G.Y. } 2010 \\
\quad\left(\mathrm{~cm}^{2}\right)\end{array}$ & $\begin{array}{c}\text { Çıkarılan } \\
\left(\mathrm{cm}^{2}\right)\end{array}$ & $\begin{array}{c}\text { Çıkarılan } \\
(\%)\end{array}$ & $\begin{array}{l}\text { Kalan G.Y. } \\
\qquad\left(\mathrm{cm}^{2}\right)\end{array}$ & $\begin{array}{l}\text { G.Y. } \\
2013 \\
\left(\mathrm{~cm}^{2}\right)\end{array}$ & $\begin{array}{l}\text { Birey } \\
\text { Say1s1 } \\
\\
2010\end{array}$ & Ç.B.S & $\begin{array}{c}\text { K.B.S. } \\
2013\end{array}$ \\
\hline Sarıkamış I-I & 8273,3 & - & - & 8273,3 & 12838,7 & 276 & - & 246 \\
\hline Sarıkamış I-II & 11495,8 & 1965,8 & 17,1 & 9530,0 & 12865,3 & 409 & 157 & 252 \\
\hline Sarıkamış I-III & 9899,8 & 2059,2 & 20,8 & 7840,6 & 11421,8 & 314 & 84 & 230 \\
\hline Sarıkamış I-IV & 10632,1 & 3816,9 & 35,9 & 6815,2 & 11345,3 & 390 & 179 & 211 \\
\hline Sarıkamış II-I & 10056,0 & - & - & 10056 & 14016,8 & 352 & - & 322 \\
\hline Sarıkamış II-II & 9376,7 & 1500,2 & 16,8 & 7876,5 & 11464,6 & 271 & 86 & 185 \\
\hline Sarıkamış II-III & 8418,1 & 1809,9 & 21,5 & 6608,2 & 9579,4 & 288 & 107 & 181 \\
\hline Sarıkamış II-IV & 10824,5 & 3842,7 & 35,5 & 6981,8 & 11876,0 & 260 & 108 & 152 \\
\hline Sarıkamış III-I & 9627,7 & - & - & 9627,7 & 12466,5 & 342 & - & 270 \\
\hline Sarıkamış III-II & 9831,4 & 1740,2 & 17,7 & 8091,2 & 11613,0 & 354 & 147 & 207 \\
\hline Sarıkamış III-III & 9791,5 & 2516,4 & 25,7 & 7263,1 & 12123,7 & 286 & 120 & 166 \\
\hline Sarıkamış III-IV & 9186,4 & 3077,4 & 33,5 & 6109,0 & 10452,1 & 297 & 126 & 171 \\
\hline Ardahan I-I & 10918,7 & - & - & 10918,7 & 15251,3 & 648 & - & 471 \\
\hline Ardahan I-II & 6254,5 & 1088,3 & 17,4 & 5166,2 & 8632,8 & 365 & 105 & 260 \\
\hline Ardahan I-III & 7269,2 & 1802,7 & 24,8 & 5466,5 & 8713,3 & 675 & 325 & 350 \\
\hline Ardahan I-IV & 11141,1 & 3620,8 & 32,5 & 7520,3 & 11388,6 & 621 & 327 & 294 \\
\hline Ardahan II-I & 7967,9 & - & - & 7967,9 & 12820,3 & 897 & - & 621 \\
\hline Ardahan II-II & 9585,5 & 1715,8 & 17,9 & 7869,7 & 12211,4 & 702 & 288 & 414 \\
\hline Ardahan II-III & 7231,6 & 1641,5 & 22,7 & 5590,1 & 10418,4 & 584 & 253 & 331 \\
\hline Ardahan II-IV & 8671,4 & 2861,6 & 33,0 & 5809,9 & 11120,5 & 615 & 319 & 296 \\
\hline Ardahan III-I & 7573,3 & - & - & 7573,3 & 12260,8 & 720 & - & 501 \\
\hline Ardahan III-II & 11070,3 & 1992,6 & 18,0 & 9077,7 & 13905,4 & 768 & 314 & 454 \\
\hline Ardahan III-III & 13797,0 & 3670,0 & 26,6 & 10127,0 & 16700,5 & 824 & 387 & 437 \\
\hline Ardahan III-IV & 9037,7 & 3244,5 & 35,9 & 5793,2 & 11245,7 & 476 & 228 & 248 \\
\hline
\end{tabular}

G.Y.; Göğüs Yüzeyi, Ç.B.S.; Çıkarılan Birey Sayısı, K.B.S.; Kalan Birey Sayısı, Parsel No: I-Kontrol, II-Zayıf Müdahale, IIIOrta Müdahale, IV-Kuvvetli Müdahale, I,II,III-Tekerrürler 


\section{Effects of precommercial thinning on stem diameter and basal area in natural stands of Scots pine (Pinus sylvestris L.)}

Çalışmada müdahale öncesi ve sonrasında ölçülen göğüs yüzeyi miktarları Tablo 5'de verilmiştir. Sarıkamış deneme alanında kontrol, zayıf müdahale, orta müdahale ve kuvvetli müdahale görmüş $1.500 \mathrm{~m}^{2}$ deneme alanında 2013 yılı sonunda kalan birey sayıs1 sirasiyla $838,644,577$ ve 535 olarak belirlenmiştir. Ardahan deneme alanında kontrol, zayıf müdahale, orta müdahale ve kuvvetli müdahale görmüş $1.500 \mathrm{~m}^{2}$ deneme alanında 2013 y1lı sonunda kalan birey sayıs1 sirasiyla 1593, 1.128, 1.118 ve 838 olarak belirlenmiştir.
Yapılan müdahalelerin göğüs yüzeyi gelişimi üzerinde istatistiksel olarak etkisinin olup olmadığını test edebilmek için 2010 yılı başlangıç göğüs yüzeyi değerleri ve 2013 yılı göğüs yüzeyi değerleri SPSS 20,0 v paket programında karşılaştırılarak varyans analizi yapılmıştır ve Tablo 6'deki değerler elde edilmiştir.

Tablo 6 incelendiğinde, blok x müdahale şekli ile yıl x blok x müdahale şekli etkileşimi hariç diğer etkileşimlerin anlamlı olduğu görülmektedir.

Tablo 6. Müdahale şekillerinin göğüs yüzeyi gelişimi etkisine ilişkin varyans analizi Table 6. Results of ANOVA for basal area by treatment

\begin{tabular}{lccrrc}
\hline \multicolumn{1}{c}{ Kaynak } & $\begin{array}{c}\text { Kareler } \\
\text { Toplam1 }\end{array}$ & df & $\begin{array}{c}\text { Kareler } \\
\text { Ortalamas1 }\end{array}$ & \multicolumn{1}{c}{ F } & $\begin{array}{c}\text { Önem } \\
\text { Düzeyi }\end{array}$ \\
\hline Y1l & 1803791,46 & 1 & 1803791,46 & 2927,646 & 0,000 \\
Bölge & 1583673,26 & 1 & 1583673,26 & 2570,383 & 0,000 \\
Müdahale Şekli & 196034,74 & 3 & 65344,91 & 106,058 & 0,000 \\
Y11 * Blok & 46814,97 & 1 & 46814,97 & 75,983 & 0,000 \\
Y11 * Müdahale Şekli & 56037,11 & 3 & 18679,03 & 30,317 & 0,000 \\
Blok * Müdahale Şekli & 4321,36 & 3 & 1440,45 & 2,338 & 0,071 \\
Y11 * Blok * Müdahale Şekli & 209,63 & 3 & 69,87 & 0,113 & 0,952 \\
Hata & 11697720,76 & 18986 & 616,123 & & \\
Toplam & 29360014,080 & 19004 & & & \\
\hline
\end{tabular}

Sarıkamış deneme alanında müdahale şeklinin göğüs yüzeyi gelişimi üzerine etkisi 2010 ve 2013 göğüs yüzeyi değerleri birlikte değerlendirildiğinde, yapılan müdahalelerin göğüs yüzeyi gelişimi üzerinde etkili olduğu ve en iyi gelişimin orta ve kuvvetli müdahale işlemlerinde gerçekleştiği gö- rülmektedir (Tablo 7). Müdahale işlemini takiben 3 y1l sonunda kontrol, zayıf müdahale, orta müdahale ve kuvvetli müdahale görmüş alanda göğüs yüzeyi /birey artış miktarları sırasıyla \%62, $\% 126, \% 134$ ve $\% 199$ olarak tespit edilmiştir.

Tablo 7. Müdahale işleminin deneme alanlarında ortalama göğüs yüzeyi $\left(\mathrm{cm}^{2}\right) /$ birey gelişimine etkisi Table 7. Effect of treatments on breast height/number of stems

\begin{tabular}{lcccc}
\hline \multirow{2}{*}{ İşlem } & \multicolumn{2}{c}{ Sarıamış } & \multicolumn{2}{c}{ Ardahan } \\
\cline { 2 - 5 } & Birey Sayıs1 & $\begin{array}{c}\text { Ortalama Göğüs } \\
\text { Yüzeyi }\end{array}$ & Birey Sayıs1 & $\begin{array}{c}\text { Ortalama Göğüs } \\
\text { Yüzeyi }\end{array}$ \\
\hline Kontrol & 1808 & $37,433 \mathrm{c}$ & 3858 & $17,310 \mathrm{c}$ \\
Zayıf Müdahale & 1678 & $39,716 \mathrm{~b}$ & 3201 & $20,052 \mathrm{~b}$ \\
Orta Müdahale & 1465 & $41,797 \mathrm{ab}$ & 2963 & $20,806 \mathrm{~b}$ \\
Kuvvetli Müdahale & 1481 & $43,428 \mathrm{a}$ & 2550 & $24,545 \mathrm{a}$ \\
\hline
\end{tabular}

Aynı sütun üzerinde bulunan benzer harfler arasında istatistik anlamda fark yoktur $(\mathrm{p}<0.05)$.

Ardahan deneme alanında müdahale şeklinin gögüs yüzeyi gelişimi üzerine etkisinin 2010 ve 2013 y1lı göğüs yüzeyi değerleri birlikte değerlendirildiğinde, yapılan müdahalelerin göğüs yüzeyi gelişimi üzerinde etkili olduğu (göğüs yüzeyi/birey) ve en iyi gelişimin kuvvetli müdahale işleminde gerçekleştiği görülmektedir (Tablo 7). Müdahale işlemini takiben 3 yıl sonunda kontrol, zayıf müda- hale, orta müdahale ve kuvvetli müdahale görmüş alanda gögüus yüzeyi/birey artış miktarları sırasıyla $\% 116, \% 155, \% 215$ ve $\% 260$ olarak tespit edilmiştir.

Müdahalelerin göğüs yüzeyi üzerine etkisi iki fark11 alanın ortalaması dikkate alınarak değerlendirildiğinde, müdahale şeklinin göğüs yüzeyi üzerinde her iki deneme alanında da benzer şekilde etkili 


\section{Sıklık bakımının doğal sarıçam (Pinus sylvestris L.) meşcerelerinde çap ve göğüs yüzeyi üzerine etkisi}

olduğu ve en yüksek göğüs yüzeyinin Sarıkamış deneme alanında kuvvetli müdahale işleminde olduğu belirlenmiştir (Tablo 7).

\section{Sonuç ve Öneriler}

Çalışma sonucunda, 2010 ve 2013 yılları sonuçlarına göre, çap gelişimi açısından en iyi gelişim kuvvetli müdahale işleminde görülmüştür. 2010 ve 2013 yılları arasındaki göğüs yüzeyi değerleri açısından da, en iyi gelişim kuvvetli müdahale işleminde tespit edilmiştir. Bu durum değerlendirirken, deneme parsellerinin çalışma öncesinde müdahale görmemiş olması ve deneme parsellerindeki birey sayıları dikkate alınmalıdır. Çalışmada, ölçülen her parametre için kuvvetli müdahale işleminin başarılı görünmesi, yapılan ilk müdahale ile parsellerde olması gereken birey sayısından daha fazla birey kaldığını ve olması gereken göğüs yüzeyi ya da birey sayısına henüz ulaşılamadığını göstermektedir.

Alandaki tüm bireylerde ölçülen çap değerlerinden hareketle, en iyi gelişimi gösteren Sarıkamış deneme alanında 2. bloktaki kuvvetli müdahale işleminin yapıldığ 1 parseldeki birey sayısı 152 adettir ve bu sayı çalışmadaki 24 parseldeki birey sayılarının en düşük olanıdır. Bu parseldeki birey sayısı hektara göre düşünülürse 3040 birey yapmakta ve bu alandaki göğüs miktarı da $2.969 \mathrm{~cm}^{2}$ olmaktadır. Ancak bu birey sayısının da yüksek olduğu kabul edilmelidir. Kuvvetli müdahale işleminde alandaki toplam göğüs yüzeyinin \%30-35'lik bir kısmının çıkarıldığı bir uygulamada, sayısal olarak alandaki bireylerin çap dağılımına bağlı olarak, birey sayısının da \%40-45'lik bir kısmı çıkarılmış olmaktadır.

Çıkarılacak göğüs yüzeyi miktarının artırılması ise meşcerede direnç kaybına neden olabileceği gibi mantar, böcek vb. doğal zararlılara da uygun ortam hazırlayabilir. Alanın bir anda açılması don çatlağ1, kar kırması ve rüzgâra karşı meşcereyi dirençsiz hale getirebilir. Bu nedenle sıklık bakımı kesimlerinin en az 2-3 defada yapılması daha sağlıklı olacaktır.

Sıklık bakımlarının amacı genellikle büyük ve yeteri kadar büyüme alanına sahip bireyleri korumaktır. Böylelikle ilk aralamada karlılık artar ve meşcerenin gelişimi düzelir (Pettersson, 1993; Varmola ve Salminen, 2004). Ayrıca ilk aralama için gerekli zaman kısalır ve maksimum ürün elde edilir (Anonim, 1997).

Sıklık bakımının çap ve boy artımı üzerine etkisinin değerlendirilmesi çalışmalarında, boy artımı üzerine etkisinin olmadığ 1 (Vuokila, 1972, Varmola, 1982, Fryk, 1984, Pettersson, 1993, Ruha ve Varmola, 1997), çok az olduğu (Vuokila, 1972; Varmola ve Salminen, 2004) veya hızlandırdığ 1 (Varmola ve Salminen, 2004) yönünde bilgiler elde edilmiştir.

Boy artımı ile ilgili farklı bilgilere karşın, sıklık bakımı kesimlerinin çap artımını önemli derecede etkilediği (Vuokila, 1972; Vestjordet, 1977; Parviainen, 1978; Varmola, 1982; Fryk, 1984; Pettersson 1993; Ruha ve Varmola, 1997) ve büyüme alanındaki artışın çap artımını hızlandırdığı ve dalların daha uzun büyüdüğü (Kellomaki ve Tuimala, 1981; Varmola ve Salminen, 2004; Fhalvik ve ark., 2005; Huuskonen ve Hynynen, 2006) belirtilmektedir.

Erken ve yoğun sıklık bakımı kesimleri çap gelişimi üzerine en kuvvetli etkiyi göstermekte, sıklık bakımı kesimleri ile gövdeler arasında geniş aralıkların bırakılması ile çap artımı da yükselmektedir (Huuskonen ve Hynynen, 2006). Gövde çaplarının küçük olduğu meşcerelerde geniş aralıklı sıklık bakımı kesimleri gövdelerin kesime olgunluk çağ1na ulaşmaları için gereken zamanı kısaltmaktadır (Anonim, 1997). Bu çalışmada, yapılan müdahalelerle elde edilen sonuçlara göre çap artımının daha önceki çalışmalarla uyumlu olduğu belirlenmiştir.

S1klık bakımı zamanı, sıklık bakımı kesimlerinin gerçekleştirileceği meşcerenin baskın boyu dikkate alınarak belirlenmektedir. Genel olarak baskın boyun 2.5-3 m olması durumunda erken (Varmola ve Salminen, 2004), 5-6 m olmasi durumunda normal (Varmola ve Salminen, 2004) ve 7-9 m olmas1 durumunda ise geç sıklık bakımı kesimleri (Ruha ve Varmola, 1997) söz konusu edilmektedir. Sıklık bakımı kesimlerinin zaman ve yoğunluğu, genç meşcerelerin kalite ve gelişimini ve bu suretle ilk aralamanın zamanını ve karlılık durumunu etkilemektedir (Huuskonen ve Hynynen, 2006). Erken aralamanın hacim artımını büyük oranda hızlandırdığı açıktır, fakat kalite değerini geç aralamalar sağlamaktadır. Genç meşcerelerde erken ve yoğun sıklık bakımı kesimleri hacim artımını hızlandırmakta ve ilk aralamada faydalanılabilir odun oranını artırmaktadır (Varmola ve Salminen 2004).

İskandinav ormancılığında sıklık bakımı kesimlerinden sonra 2000 den 4000'e kadar gövdenin alanda bırakılması ekonomik ve silvikültürel açıdan en uygun oranlar olarak önerilmektedir (Vuokila, 1972; Vestjordet, 1977; Pettersson, 1993; Salminen ve Varmola, 1990; Varmola, 1996; Ruha ve Varmola, 1997; Varmola ve Salminen, 2004).

Yapılan bu çalışmada, en yüksek çap ve göğüs yüzeyi değerlerinin Sarıkamış deneme alanında kuvvetli müdahale işlemini takiben 3560 bireyin kald1ğ1 deneme alanında ve Ardahan deneme alanında 


\section{Effects of precommercial thinning on stem diameter and basal area in natural stands of Scots pine (Pinus sylvestris L.)}

kuvvetli müdahale işlemini takiben yaklaşık 5600 bireyin kaldığı kuvvetli müdahale deneme alanında olduğu tespit edilmiştir. İki deneme alanı karşılaştırıldığında Sarıkamış deneme alanında daha yüksek çap ve göğüs yüzeyi değeri elde edildiği belirlenmiştir.

Genç sarıçam meşcerelerinde sıkışıklığın fazla olması, gövde çapı ve dal gelişiminin yavaş olmasına neden olmaktadır. Ormancılık uygulamalarında her ne kadar şablon niteliğinde rakam ve miktardan bahsetmek sakıncalı olsa da, bu çalışmadaki iki farklı deneme alanında bulunan miktarları ortalama değer olarak kabul etmek, çalışma yapılan alanların özelliklerindeki sıklık çağındaki doğal sarıçam meşcerelerine uygulanacak bakım tedbirlerinde genel çizgiyi belirlemede bir gösterge olabilecektir. Bu açıdan, sıklık bakımı önlemlerinin mutlaka yapılması, ihmal edilmemesi gerektiği düşünülmelidir. Bonitet, bakı, alanın yaşı vb. gibi faktörlerde sıklık bakımı kesimlerinin uygulanışında etkili olmaktadır. Bireylerin alanda homojen dağılımının sağlandığ 1 ve öncelikle menfi seleksiyon şeklinde alanda bırakılması istenmeyen bireylerin çıkarıldığı sıklık bakımı müdahalesi uygulanmal1dır. Bu çalışma sonucunda, iki farklı deneme alanı dikkate alındığında doğal sarıçam meşcerelerinde ilk sıklık bakımı kesimlerinde hektardaki birey sayısının 3.000-4.000 civarında olmasının uygun olacağ 1 ifade edilebilir.

\section{Teşekkür}

Orman Genel Müdürlüğ, Doğu Anadolu Ormanc1lık Araştırma Enstitüsü Müdürlüğü, Silvikültür ve Botanik Araştırmaları Bölüm Başmühendisliğince yürütülmekte olan 01.2103/2009-2018 proje nolu "Sıklık Bakımının Doğal Sarıçam (Pinus sylvestris L.) Meşcerelerinde Çap ve Gögüs Yüzeyi Üzerine Etkisi" adlı proje çalışmasının ilk ara sonucu bu makale ile yayımlanmaktadır. Çalışmanın planlanma aşamasından yayımlanmasına kadarki sürede emeği geçen herkese teşekkür eder, ormancılık bilimine ve uygulamalarına katkısı olmasını temenni ederim.

\section{Kaynaklar}

Alemdağ, Ş., 1967. Türkiye'deki Sarıçam Ormanlarının Kuruluşu, Verim Gücü ve Bu Ormanların İşletilmesinde Takip Edilecek Esaslar. Orm. Arş. Enst. Teknik Bülten Serisi No: 20. Ankara.

Anonim, 1997. Stand Management: using precommercial thinning to enhance woodland productivity. Oregon State University Extension Service, The Woodland Workbook, EC 1189.

Atay, İ., 1971. Tabii Gençleştirmenin Başarılı veya Ba- şarısız Oluşuna Etki Yapan En Önemli Faktörler Üzerine Araştırmalar. İ.Ü. Orm. Fak. Yay. Cilt: 21, Sayı: 2.

Atay, İ., 1984. Orman Bakımı. İ.Ü. Or. Fak. Yayınları No: 3196/356. İstanbul.

Boratynski, A., 1991. Range of Natural Distribution. In: Genetics of Scots pine (Giertych, M., Matyas, C. Eds.). Elsevier Publication. pp: 19-27. Amsterdam.

Fahlvik, N., Ekö, P-M. and Pettersson, N. 2005. Influence of precommercial thinning grade on branch diameter and crown ratio in Pinus sylvestris in southern Sweden. Scandinavian Journal of Forest Research 20: 243-251.

Fryk, J., 1984 Wide Spacing after Cleaning of Young Forest Stands - Stand Properties and Yield. Report 13, Department of Forest Yield Research, Swedish University of Agricultural Sciences, Garpenberg, pp.1-153.

Huuskonen, S., Hynynen, J., 2006. Timing and intensity of procommercial thinning and their effects on the first commercial thinning in Scots pine stands. Silva Fennica 40 (4): 645-661.

Hynynen, J., 1995. Predicting tree crown ratio for unthinned and thinned Scots Pine stands. Canadian Journal of Forest Research 25: 57-62.

Johanson, K., 1992. Effects of initial spacing on the stem and branch properties and graded guality of Picea abies (L.) Karst. Scandinavian Journal of Forest Research 7: 503-514.

Karadağ, M., 2013. Ankara Orman Bölge Müdürlüğünde Sarıçam (Pinus sylvestris L.)'ın Doğal Gençleştirme Koşullarının Belirlenmesi. OGM İç Anadolu Ormancılık Araştırma Enstitüsü Müdürlüğü yayınları, No: 299. Ankara.

Kayacık, H., 1963. Türkiye çamları ve bunların coğrafi yayılışları üzerine araştırmalar. İ.Ü. Orman Fakültesi Dergisi Seri A 13: 1-17.

Kellomäki, S., Tuimala, A., 1981. Effect of stand density on branchiness of young Scots pines. Folia Forestalia 478: 1-27.

Makinen, H., 1996. Effect of intertree competition on branch characteristics of Pinus sylvestris Families. Scandinavian Journal of Forest Research 11: 129-136.

Parviainen, J., 1978. Taimisto-ja Riukuvaiheen Ma "Nniko" Nharvennus. Referat: Durchforstung im Kiefernbestand inder Jungwuchs-und Stangenholzphase. Folia Forestalia 346, 40 pp (Almanca özetli Fince Yayın).

Pettersson, N., 1993. The effect of density after precommercial thinning on volume and structures in Pinus sylvestris and Picea abies stands. Scandinavian Journal of Forest Research 8: 528-539.

Pravdin, L.H., 1969. Scots pine variation, Intraspecific taxonomy and selection. USDA For. Serv. 208 p, Washington D.C. 


\section{Sıklık bakımının doğal sarıçam (Pinus sylvestris L.) meşcerelerinde çap ve göğüs yüzeyi üzerine etkisi}

Ruha, T., Varmola, M., 1997. Precommercial thinning in naturally regenerated scots pine stands in northern Finland. Silva Fennica 31: 401-415.

Saatçioğlu, F., 1971. Orman Bakımı. İ.Ü. Orm. Fak. Yayınlar1 No: 1636/160. İstanbul.

Saatçioğlu, F., 1976. Silvikültür I. Silvikültürün Biyolojik Esasları ve Prensipleri. İ.Ü. Orman Fak. Yayınları, Yayın No 2187/222, İstanbul.

Skilling, D.D., 1990. Pinus sylvestris. In: Silvics of North America. Vol. 1. Conifer. (Russell, M.B. Barbara, H.H. eds.). USDA Agr. Handbook.454. pp: 489-496. Washington, D.C.

Ulvcrona, K. A., Claesson, S., Sahlen, K., Lundmark, T., 2007. The effects of thinning and stand density on stem form and branch characteristics of Pinus sylvestris. Forestry 80 (3): 323-335.

Varmola, M., 1982. Taimikko- ja riukuvaiheen männikönkehitys harvennuksen jälkeen. Summary: Development of Scots pine stands at the sapling and pole stages after thinning. Folia Forestalia 524.31 p.

Varmola, M. and Salminen, H. 2004 Timing and intensity of precommercial thinning in Pinus sylvestris stands. Scandinavian Journal of Forest Research 19: 142-151.

Vestjordet, E., 1977. Precommercial thinning of young standsof Scots pine and Norway spruce: I: Data stability, dimension distribution, etc. Medd. Norsk Inst. Skogforsk 33: 314-436.

Vuokila, Y., 1972. Treatment of seedling stands from the viewpoint of production. Folia Forestalia 141, 36 p.

Vuokila, Y., 1981. The growth reaction of young pine stands to the first thinning. Folia Forestalia 468, 13 p.

Yıldızbakan, A., Saraçoğlu, Ö., Akgün, C., Aydın, A.C. 2013. Sedir Meşcerelerinin Hacim Artımını Maksimize Eden Optimum Kuruluşlar, OGM Doğu Akdeniz Ormancılık Araştırma Enstitüsü Müdürlüğü Yayınları, Yayın No: 69, Teknik Bülten No:43, Sayfa 183, Tarsus. 